Bolm Inst. oceanogr., S Paulo, 28(2):29-36, 1979

\title{
PRODUÇÃO PRIMÄRIA DE PTEROCLADIA CAPILLACEA (GELIDIACEAE - RHODOPHYTA)
}

\section{LUIZA SUMIKO KINOSHITA* \& CLOVIS TEIXEIRA**}

* Departamento de Morfologia e Sistemática Vegetais, Universidade Estadual de Campinas

** Instituto Oceanográfico da Universidade de São Paulo

\section{Synopsis}

Primary production in Pterocladia capillacea was measured by means of oxygen evolution (Winkler's Method) under controlled conditions. The method which utilizes light and dark bottles in studies of productivity in phytoplankton has been adopted for the estimation of primary production in macroscopic benthic algal. Satisfactomy results were obtained when $1.0 \mathrm{ml}$ by volume of alga in a $270 \mathrm{ml}$ bottle at 24.0 to $28.0^{\circ} \mathrm{C}$ was iluminated at an incandescent light intensity of $40.0 \mathrm{Klux}$ for a period of 2 hours. This method should be applicable to other algal of similar mor phology to $P$. capillacea.

\section{Introdução}

Os estudos relativos à produção primāria têm sido objeto de inúmeras pesquisas como resultado do desenvolvimento de novos métodos de investigação, aplicados principalmente a organismos fitoplanctônicos marinhos (Gaarder \& Gran, 1927; SteemannNielsen, 1952; Ryther, 1954; Strickland, 1958; Steele, 1956), ou de água doce (Goldman, 1961; Verduin, 1956; Talling, 1965).

Por sua vez, estudos sobre a produtividade do fitobentos, constituído pelas algas "superiores" na sua maioria, são ainda escassos e fragmentários em todo o mundo, provavelmente como uma decorrência da dificuldade em se aplicar a este tipo de plantas os métodos desenvolvidos para o fitoplâncton. Neste campo, destacam-se os trabalhos de Blinks (1955), Pomeroy (1959, 1961), Grфntved (1958), Odum et al. (1958), Westlake (1965a) e Doty (1967).

No Brasil jā existem vários trabalhos sobre produtividade do fitoplâncton (Teixeira \& Tundisi, 1967; Teixeira, 1969; Tundisi, 1969; Teixeira et al., 1969), mas nada foi feito ainda no que se refere às algas bentônicas.

Este trabalho visou ao desenvolvimento de uma metodologia adequada, adaptada daquela aplicada ao fitoplâncton, para o estudo da produtividade de algas bentônicas da zona das marés. Os experimentos foram realizados com Pterocladia capilla-

Publ. n! 447 do Inst. oceanogr. da Usp. cea (Gme1.) Bornet et Thuret, rodofícea comum e abundante durante o ano todo em nosso litoral, através da dosagem química de oxigênio dissolvido.

Material e métodos

A escolha de $P$. capillacea decorre não apenas da conveniência prática que a espécie apresenta a este tipo de investigação, devido à morfologia do seu talo, mas, também, por se tratar de uma espécie cuja biologia e ecologia é das mais conhecidas dentre as algas da costa brasileira, aliando-se a is to o seu grande valor econômico como matéria prima para a extração de ficocolóides (Oliveira Filho \& Sazima, 1973).

Os trabalhos de campo foram realizados nos arredores de Ubatuba, SP. Este local, além de apresentar facilidades técnicas para o desenvolvimento dos trabalhos de laboratório, tem também uma flora marinha bentônica bem conhecida (Joly, 1965).

A estimativa da produção primária de P. capillacea foi feita pelo método de Winkler modificado segundo Magliocca (1966). Foram utilizados frascos transparentes $\left(F_{t}\right)$ e pretos $\left(F_{p}\right)$, baseados na técnica de Gaarder \& Gran(1927), contendo amostra de alga mais água do mar filtrada. A capacidade média dos frascos era de $270 \mathrm{~m} 1$. Para incubação, adotouse a técnica usada por Teixeira (1969) em estudos de fitoplancton.

0 trabalho processou-se segundo as etapas: 
Plantas inteiras foram removidas de uma determinada área na praia Domingas Dias, tendo-se medido a temperatura em cada ocasião. Coletou-se ainda água em reservatório plástico para os trabalhos de laboratório, a qual foi filtrada em filtros "Millipore" H. A. com porosidade de $0,45 \mu$. As algas foram lavadas e selecionadas com eliminação das partes basais, e a quantidade utilizada para cada frasco foi determinada por deslocamento de volume (Fig. 1).

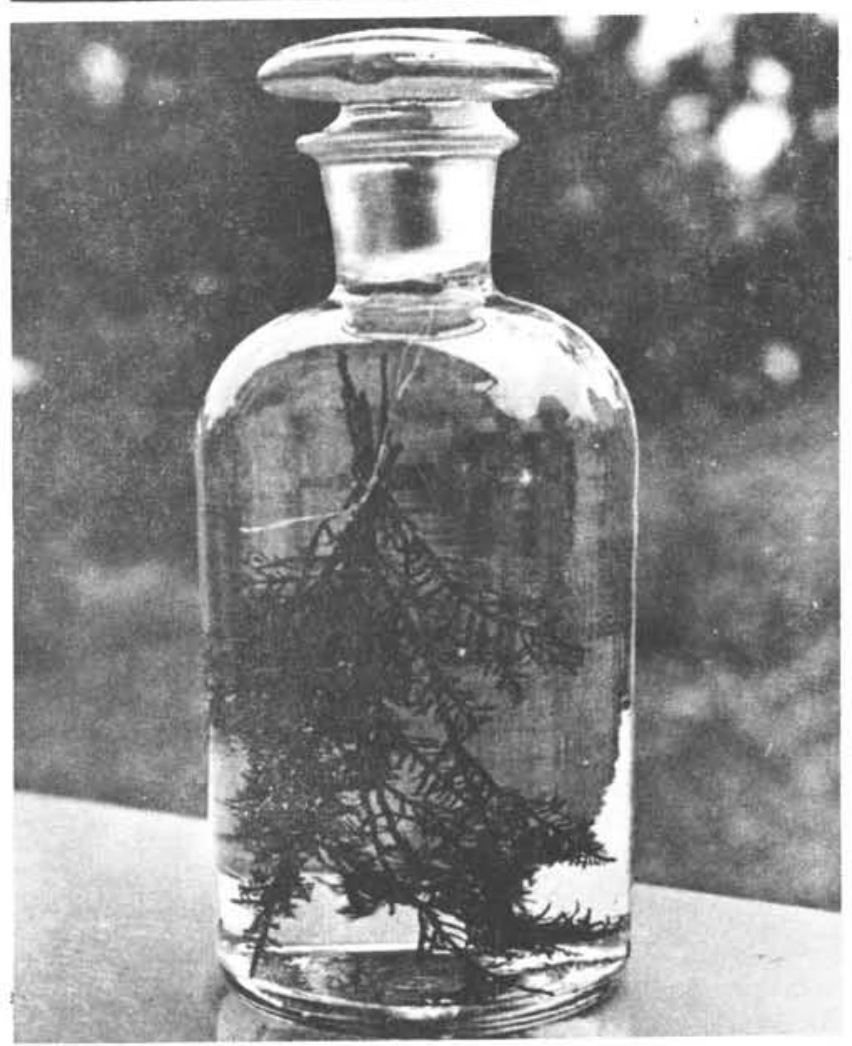

Fig. 1. Aspecto de uma amostra preparada.

Os frascos pretos foram envolvidos em papel-alumínio. Além dos frascos transparentes e pretos contendo a alga junto, foram preparados frascos somente com a água filtrada para a dosagem do oxigênio inicial. O período de incubação em luz incandescente variou de 1 a 4 horas, de acordo com o objetivo de cada experimento.

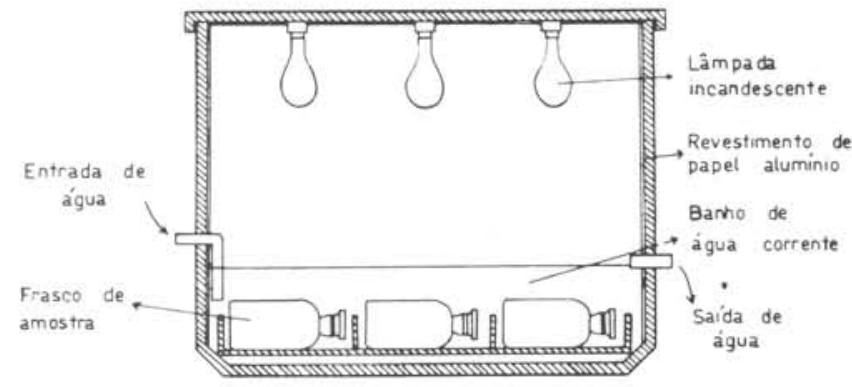

Fig. 2. Disposição das amostras no incubador.
A intensidade luminosa média no incubador era de 40,0 Klux, e a temperatura variou de 24 a $28^{\circ} \mathrm{C}$. Após a incubação, as amostras foram fixadas e, após a retirada das algas, o conteúdo dos frascos foi titulado. Para os cálculos de produção, foi considerada a alteração do volume de água existente no frasco devido à introdução da alga, além dos reagentes. As algas foram lavadas com água destilada, secadas em estufa a $105^{\circ} \mathrm{C}$, dessecadas e, por fim, pesadas. Foram testados vários períodos para secagem na estufa e esfriamento no dessecador, sendo que não houve diferenças nos resultados a partir de 2 horas na estufa e 1 hora no dessecador.

Por ocasião de cada coleta, foram analisados os seguintes parâmetros ambientais: temperatura da água, salinidade (Harvey, 1955), oxigênio dissolvido "in loco" (Magliocca, 1966), fosfato inorgânico dissolvido (Strickland \& Parsons, 1968), e matéria particulada (Teixeira \& Kutner, 1963).

\section{Experimentos realizados}

Vários experimentos foram realizados com o objetivo de se estabelecer uma metodologia adequada a ser usada como rotina na avaliação da produção de algas macroscópicas:

\section{Efeito da presenca de alga nos frascos} para a fixacão do oxigênio inicial

Preparou-se 3 lotes de frascos transparentes, contendo o 19 lote apenas água filtrada, e os demais, água mais $2,0 \mathrm{ml}$ de alga. No 29 lote, retirou-se a alga imediatamente após a fixação e, no 3 ? , as algas foram conservadas dentro dos frascos até a acidificação.

\section{2. "Metabolismo" da água do mar filtrada}

2 lotes de frascos com a água filtrada foram preparados, sendo que um ficou exposto à 1 uz por 3 horas à temperatura de $24^{\circ} \mathrm{C}$ para depois ser fixado e, o outro, foi fixado imediatamente após a preparação.

\section{Efeito do volume de alga na producão} de oxigênio

3 lotes de frascos transparentes contendo $1,0,1,5$ e $2,0 \mathrm{ml}$ de alga ficaram expostos por 2 horas à $1 \mathrm{uz}$, à temperatura de $26^{\circ} \mathrm{C}$. 
4. Variação do tempo de exposigão à luz 4 lotes de frascos transparentes e pretos contendo $2,0 \mathrm{~m} 1$ de alga ficaram expostos à 1 uz por períodos de 1 , 2,3 e 4 horas à temperatura de $28^{\circ} \mathrm{C}$.

5. Efeito da retirada da alga para a fixaça das amostras

2 lotes de frascos transparentes e pretos contendo $1,0 \mathrm{ml}$ de alga $\mathrm{fi}-$ caram expostos à 1 uz por 2 horas à temperatura de $24^{\circ} \mathrm{C}$. Após a incubação, num lote, as algas foram retiradas dos frascos para fixação das amostras, e no outro a fixação foi feita com as mesmas dentro dos frascos, sendo retiradas imediatamente.

6. Efeito do sifonamento na determinação do oxigênio dissolvido

2 lotes de frascos transparentes e pretos contendo $2,0 \mathrm{~m} 1$ de alga ficaram expostos à 1 uz por 2 horas à temperatura de $26^{\circ} \mathrm{C}$. Após a fixação, as algas foram retiradas imediatamente, fazendo-se sifonamento para frascos menores apenas em 1 lote.

\section{Resul tados}

Os parâmetros ambientais do local de coleta (Tab. I) oscilaram muito, principalmente em relação a fosfato inorgânico e matéria particulada. Os valores de temperatura, salinidade e oxigênio dissolvido "in loco" concordam com os obtidos por outros autores para a região de Ubatuba.

Tabela I - Parâmetros ambientais do local de coleta

\begin{tabular}{|c|c|c|c|c|c|c|}
\hline \multirow[t]{2}{*}{ Data } & \multirow{2}{*}{$\begin{array}{l}\text { TERPERATUAA } \\
\text { ("S) }\end{array}$} & \multirow{2}{*}{$\begin{array}{c}\text { SALIMIDADE } \\
(* / \ldots)\end{array}$} & \multirow{2}{*}{$\begin{array}{l}\text { oxisenio } \\
\text { (nim) }\end{array}$} & \multirow{2}{*}{$\begin{array}{l}\text { COSFATO INORG, DISSOLV. } \\
\text { (Wg-atil) }\end{array}$} & \multicolumn{2}{|c|}{$\begin{array}{c}\text { NATEATA PARTICULAON } \\
\left(\operatorname{mg} / \mathrm{An}^{-3}\right)\end{array}$} \\
\hline & & & & & argän. & inergàn. \\
\hline ASO, 71 & 26,3 & $\ldots$ & $\ldots$ & $\ldots$. & $\ldots$ & $\ldots$ \\
\hline str. 71 & 18,0 & 34,80 & 4.99 & $\cdots$ & 22,30 & 16,10 \\
\hline nov. $n$ & $2 t, 0$ & 34.15 & 5.02 & 0.29 & 6,60 & 6,36 \\
\hline JAN, 12 & 27.0 & 33,05 & 4.91 & 0,40 & 1.4. & 3.38 \\
\hline mas. 72 & 26,0 & 32,91 & 4,22 & 0,20 & 6,61 & 17.48 \\
\hline$\triangle \theta \times, 72$ & 26.0 & 31.47 & 4.52 & 1.10 & 16.75 & 4,62 \\
\hline rail, 72 & 23.0 & 34.61 & 4.87 & $\ldots$ & 5.19 & 11,00 \\
\hline sut. 72 & 21.5 & 35.55 & 4.68 & $\cdots$ & $\ldots$ & $\cdots$, \\
\hline 460,77 & 19.5 & 35.19 & +.92 & $\ldots$ & $\ldots$ & $\ldots{ }^{\prime}$ \\
\hline SET. 72 & 22,5 & 35.04 & 4.73 & $\ldots$ & $\ldots$ & $\ldots$ \\
\hline sov $n$ & 23,0 & 32.36 & 4.60 & & $\cdots$ & $\cdots$ \\
\hline
\end{tabular}

\section{Experimentos realizados}

1. Efeito da presensa de alga nos frascos durante a fixação do oxigênio inicial

Houve aumento da quantidade de oxigênio dissolvido em presença de alga, sendo que o maior aumento ocorreu no
20 lote, em que o conteúdo foi sifonado ( $\mathrm{Tab}$. II).

Tabela 11 - Efeito da presença de alga nos frascos para a fixação do oxigênio inicial

\begin{tabular}{|c|c|c|c|}
\hline MESES & $\begin{array}{c}\text { FRASCO SEM ALCA } \\
\left(m \mid 0_{2} / 1\right)\end{array}$ & $\begin{array}{c}\text { FRASCO COM ALGA E } \\
\text { SIFONADO } \\
\left(m \mid \mathrm{D}_{2} / 1\right)\end{array}$ & $\begin{array}{c}\text { FRASCO COM ALGA E } \\
\text { NAO SIFONADO } \\
(m 10, / 1)\end{array}$ \\
\hline \multirow[t]{2}{*}{ JAN. 72} & 4,26 & 4.70 & 4.18 \\
\hline & 4,28 & 4.72 & 4,48 \\
\hline \multirow[t]{2}{*}{ MAR. 72} & 2,99 & 4,36 & 3,51 \\
\hline & 3,19 & 4.43 & 3.60 \\
\hline \multirow[t]{2}{*}{$A G 0.72$} & 3.53 & 3.98 & 3,67 \\
\hline & 3,54 & 4.10 & 3.74 \\
\hline
\end{tabular}

2. "Metabolismo" da água do mar filtrada Praticamente não houve alteração de oxigênio dissolvido após o período de incubação, o que indica uma eficiência na filtração (Tab. III).

Tabela III - "Metabolismo" da ägua do mar filtrada

\begin{tabular}{lcc}
\hline MESES & $\begin{array}{c}\text { OXIGENIO INICIAL } \\
(\mathrm{m} 1 / 1)\end{array}$ & $\begin{array}{c}\text { OXIGENIO APOS EXPOSICCAO A LUZ } \\
(\mathrm{m} 1 / 1)\end{array}$ \\
\hline SET. 71 & 3,58 & 3.58 \\
JUL. 72 & 3,54 & 3.55 \\
& 3,59 & 3,56 \\
SET. 72 & 2,83 & 2,83 \\
& 2,86 & 2,85 \\
& 2,87 & 2,88 \\
\hline
\end{tabular}

3. Efeito do volume de alga na producão de oxigênio

Observa-se uma diminuição gradativa na razão de produção com aumento da quantidade de alga nos frascos ( $\mathrm{Tab}$. IV).

Tabela IV - Efeito do volume de alga na produção de oxigênio

\begin{tabular}{cccc}
\hline & \multicolumn{3}{c}{ VOLUME DE ALGA $(m 1)$} \\
\cline { 2 - 4 } & 1.0 & 1.5 & 2.0 \\
& 11.13 & 9.44 & 7.71 \\
PRODUÇAO LTQUIDA & 11,18 & 10.03 & 9.04 \\
(m) $0,2 / 9 / \mathrm{h})$ & 12.33 & 10.13 & 9.07 \\
& 12.55 & 10.85 & 9.79 \\
\hline
\end{tabular}

4. Variacão do tempo de exposicão à luz A razão de produção diminui com maior período de incubação (Tab. V) . 
Tabela V - Variação do tempo de exposição à luz

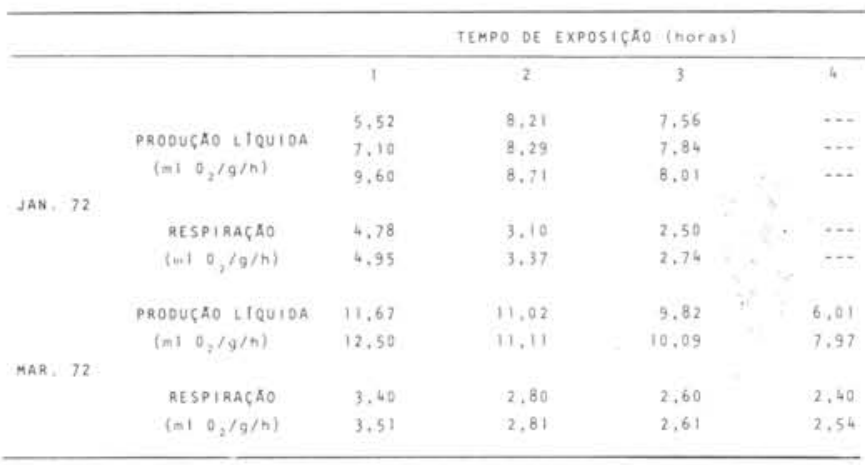

5. Efeito da retirada da alga para a fixação das amostras

Houve um ligeiro acréscimo de oxigênio nos frascos em que a fixação foi feita após a retirada da alga (Tab. VI).

Tabela VI - Efeito da retirada da alga para a fixação das amostras

\begin{tabular}{|c|c|c|c|}
\hline & $F I X A C ̧ A O$ & APOS RETIRADA & EIXACSAD SEM RETIRADA \\
\hline \multirow{4}{*}{$\begin{array}{l}\text { PRODUÇAO I IQUIDA } \\
(m \mid 0, / g / n)\end{array}$} & & 10.89 & 9.88 \\
\hline & & 10.95 & 10.08 \\
\hline & & 11,20 & 10.26 \\
\hline & & 11,53 & 10.43 \\
\hline \multirow{3}{*}{$\begin{array}{l}\text { RESP I RACGAO } \\
\text { (t) } 0, / 9 / h)\end{array}$} & & 2,18 & 1,57 \\
\hline & & 2.25 & 1.86 \\
\hline & & 2.42 & 2.09 \\
\hline
\end{tabular}

6. Efeito do sifonomento na determinasão do oxigênio dissolvido

As diferenças obtidas entre os fras$\cos$ em que o conteúdo foi sifonado com aqueles que não o foram após a retirada das algas são desprezíveis, considerando-se as variações da própria amostragem (Tab. VII).

Tabela VII - Efeito do sifonamento na determinação do oxigênio dissolvido

\begin{tabular}{|c|c|c|c|}
\hline RESES & & SIFONADO & NAO SIFONADO \\
\hline & & 9,12 & 8,37 \\
\hline & PRODUÇAO LIQUIDA & 9,52 & 8.55 \\
\hline & & 9.72 & 9.74 \\
\hline & & 11,34 & $\cdots$ \\
\hline \multicolumn{4}{|l|}{ MAR, 72} \\
\hline & RESPIRAÇAOAO & $\begin{array}{l}1,84 \\
1,95\end{array}$ & 1.61 \\
\hline & $\{=10, / g / h)$ & $\begin{array}{l}2,93 \\
2,18\end{array}$ & $\begin{array}{l}1.82 \\
1.99\end{array}$ \\
\hline & & 9.63 & 9,41 \\
\hline & PRODUÇAO LIQUIDA & 10.58 & 9.83 \\
\hline & $\left(-10_{2} / g / h\right)$ & 11,27 & 9.93 \\
\hline & & 11.30 & 11.01 \\
\hline \multicolumn{4}{|l|}{ ABR. 72} \\
\hline & & 2,12 & 2.07 \\
\hline & RESPIRACAO & 2.18 & 2.10 \\
\hline & $\left.(\mathrm{m}) \mathrm{O}_{\mathrm{z}} / \mathrm{g} / \mathrm{h}\right)$ & 2,35 & 2,31 \\
\hline & & 2,51 & 2.33 \\
\hline
\end{tabular}

\section{Discussão}

O método de Winkler ê comparável às técnicas manométricas de Warburg utilizadas por Emerson \& Green (1934) e outros, em estudos de fotossíntese e respiração de plantas aquáticas (Ryther, 1956). 0 método do $\mathrm{C}^{14}$, apesar da maior sensibilidade, dá valores acima do ponto de compensação, intermediários entre a produção 1î́quida e bruta (Vaccaro \& Ryther, 1954).

Fontes de erro, como perda de oxigênio por aumento de temperatura ambiente (Martin, 1968) e perda de iodo por volatilização se a titulação é retardaḍa, podem introduzir erro na dosagem do oxigênio (Montgomery et al., 1964). Neste método, o erro têcnico varia de 1 a $2 \%$ (Tseng \& Sweeney, 1946).

Através da filtração, a água utilizada nos experimentos ficou isenta de fitoplâncton, bactérias e material particulado maior que $0,45 \mu$. Com a lavagem das algas nesta água, procurou-se eliminar ao máximo as algas epífitas, briozoários, poliquetos, moluscos, microcrustáceos, etc.

Os estágios diferentes de desenvolvimento durante o ano todo dificultarama seleção da amostragem, e provavelmente contribuíram para explicar parte da variação obtida. A eliminação da parte basal das frondes foi feita no sentido de se ter um volume de material metabolicamente mais ativo.

Vollenweider (1969) critica este procedimento, justificando que ele implica numa variação na tomada de nutrientes quando se separa a fronde da parte basal, além da alteração no comportamento quando esta è separada do substrato. Segundo Oliveira Filho \& Sazima (1973), a propagação vegetativa desta alga ê muito eficiente, havendo brotamento nos ramos cortados, o que evidencia um metabolismo ativo mesmo sem a parte basal. Considerando a técnica utilizada para avaliação da razão fotossintética e o tamanho médio de $P$. capillacea, os valores obtidos com a planta sem a parte basal corresponde provavelmente à produção global das plantas, embora não se tenha feito um controle com plantas inteiras.

A relação entre peso seco e volume apresentou uma variação da ordem de até $15 \%$, o que mostra que o método empregado é razoável para este tipo de determinação. Deve ser lembrado, entretanto, que a eficiência fotossintética pode não estar diretamente relacionada com o peso seco e sim com a área da fronde, estado fisiológico e a quantidade de pigmentos. 
Quanto ao número de frascos utilizados nas determinações (réplicas), houve uma variação de acordo com o objetivo do experimento. Utilizou-se 14 frascos no máximo para se obter uma disposição equivalente em relação à fonte de $1 \mathrm{uz}$, além do espaço no incubador, do tempo gasto para a seleção e lavagem das frondes e da análise química das amostras.

Os valores de oxigênio inicial da água do mar variaram nas diferentes ocasióes, dado que também deve ser considerado na comparação das razões de produção. 0 período de indução de 10 minutos foi determinado empiricamente para $P$. capillacea, sendo que Tseng \& Sweeney (1946) utilizaram um período de 20 a 30 minutos para Gelidium, gênero da mesma família.

Levring (1946) justifica este período argumentando que o mesmo é necessārio para neutralizar uma possível influência inibitória de um brusco aumento de luz.

0 aumento de oxigênio inicial observado nos frascos fixados em presença da alga deve ser devido ao metabolismo da amostra nesse pequeno intervalo de tempo em luz ambiente, até a fixação completa (Tab. II). Entre as amostras sifonadas e as mantidas no mesmo frasco, houve aumento no caso das primeiras devido ao problema de aeração no processo de transferência. As algas mantidas dentro dos frascos após a fixação causaram um pequeno aumento de oxigênio em relação aos resultados obtidos com frascos que continham somente ägua do mar, devido talvez à continuação dos processos metabōlicos mesmo na presença de excesso de reagentes. Por outro 1 ado, pode ocorrer incorporação de iodo pelas algas durante este período, concomitantemente com a fixação de oxigênio, o que justifica valores de oxigênio intermediários entre os frascos que foram sifonados e os que continham apenas água do mar.

Uma das críticas ao método utilizado é o efeito da respiração bacteriana que pode mascarar os valores da produção. Mesmo utilizando água do mar filtrada, hã inoculação através das próprias paredes dos frascos (Verduin, 1960).

Vaccaro \& Ryther (1954) não constataram diferença significante entre a respiração bacteriana nos frascos transparentes e pretos, vālido para exposição de até mais de 24 horas. Qasin \& Bhattathiri (1971) não encontraram nenhuma variação de oxigênio nos $F_{p}$ e menos oxigênio nos $\mathrm{F}_{\mathrm{t}}$ após 2 a 3 horas de incubação. Conforme Pratt \& Berkson (1959), os efeitos da respiração através dos frascos pretos para períodos curtos podem ser despreza- dos, considerando-se que a atividade bacteriana seja semelhante tanto no claro como no escuro. Não se evidenciou nenhuma atividade bacteriana durante o período de incubação (Tab. III). Um possíve1 inóculo de bactérias através das paredes dos frascos não foi detectado, talvez em consequiência das variações entre as prōprias réplicas.

Através dos resultados da Tabela IV, podemos observar que houve maior eficiếncia de produção $\operatorname{com} 1,0 \mathrm{~m} 1$ de alga, que com quantidade maior da mesma. Este aumento de razão de luz-reação fotoquímica, como conseqüência da diminuição de sombreamento. Entretanto, não se pode reduzir demasiadamente a quantidade de a1ga, pois is to implica num aumento relativo do erro na determinação do peso seco, e mesmo na titulação do oxigênio. Um outro fator a ser levado em conta ề a quantidade limitante de $\mathrm{CO}_{2}$ disponível para ser absorvido e que poderia estar limitando a produção.

Considerando a quantidade de material utilizada nos experimentos, a produção líquida foi relativamente alta quando comparada com dados de Odum et al (1958) para outras espécies de algas. Todavia, deve ser lembrado que houve diferenças na quantidade de material utilizado para cada frasco, tempo de exposição à luz, além das diferenças metabólicas inerentes às próprias plantas. Estes fatos dificultam muito, e tornam mesmo arriscadas as comparações de produtividade entre os dados da literatura, em virtude da metodologia empregada pelos värios autores.

Para experimentos com luz artificial, o período de 2 horas de incubação jā é suficiente (Tab. V). Após 1 hora, obtémse uma variação considerável entre as réplicas pela menor quantidade de oxigênio produzido. Se se deixar por 3 horas, a razão de produção decresce, embora as réplicas apresentem uma variação entre si bem menor. Novamente neste caso, a diminuição da razão de produção num tempo prolongado de incubação poderia ser devida à limitação de $\mathrm{CO}_{2}$ dentro dos frascos.

0 pequeno aumento de oxigênio verificado nos frascos em que a fixação foi feita após a retirada das algas (Tab. VI) pode ser devido à interação da bolha de ar presente nos frascos no ato da retirada da alga. Por outro lado, hâ a garantia de que não houve efeito dos reagentes sobre as algas, proporcionando alterações no conteúdo dos frascos e, eventualmente, no peso seco das algas. Apesar do referido aumento, esta técnica utilizada para a fixação das amostras parece ser bastan- 
te satisfatōria, pois evita o problema do metabolismo das algas mesmo na presença dos reagentes e também uma possível incorporação de iodo pelas mesmas.

As amostras que não foramsifonadas para frascos de volume menor, apesar da boTha de ar que restou após a retirada das algas, apresentaram menor variação entre as réplicas (Tab. VII). 0 erro de sifonamento ocorreu principalmente nas amostras em que houve borbulhamento durante a transferência, resultando num aumento no teor de oxigênio.

\section{Conclusões}

1. Considerando os resultados obtidos nos experimentos, o método de Winkler érecomendável para o estudo comparativo de produção primária de algas macroscópicas, desde que se estabeleça um roteiro de metodologia.

2. A quantidade de $1,0 \mathrm{ml}$ de alga para frascos de $270 \mathrm{ml}$, temperatura variando entre 24,0 e $28,0^{\circ} \mathrm{C}$ e intensidade luminosa de 40,0 Klux, proporcionou resultados satisfatórios, tendo-se em vista a alta eficiência de produção e a pequena variação entre as réplicas.

3. 0 período de incubação de 2 horas pode ser usado em laboratório, com intensidade luminosa de 40,0 Klux.

4. A fixação das amostras após a incubação pode ser realizada com as algas dentro dos frascos, seguida de sua retirada imediata, ou também com a retirada das plantas um pouco antes de se colocar os reagentes.

\section{Agradecimentos}

Ao Dr. Eurico Cabral de Oliveira Filho, pelas inúmeras críticas e sugestões.

À Fundação de Amparo à Pesquisa do Estado de São Paulo, pela concessão de Bolsa (processo Biológicas 70/429) por ocasião da realização do presente trabalho, ao primeiro autor.

Ao Instituto Oceanogräfico da Universidade de São Paulo, pelas facilidades concedidas na utilização dos laboratórios de Ubatuba e São Paulo.

\section{Resumo}

A produção primária de Pterocladia capillacea foi medida através da dosagem de oxigênio (método de Winkler) em condições de laboratório, utilizando-se luz incandescente.

Foi discutida em detalhe, uma metodo- logia adequada para a avaliação da produção primäria de algas bentônicas macroscópicas, usando-se frascos transparentes e pretos, com base naquela utilizada para estudos de fitoplâncton. A quantidade de 1,0 ml de alga para frascos com capacidade de $270 \mathrm{ml}$, temperatura entre 24,0 e $28,0^{\circ} \mathrm{C}$, intensidade luminosa de $40,0 \mathrm{~K} 1 \mathrm{ux}$ e período de incubação de 2 horas, apresentaram resultados satisfatórios.

Esta metodologia pode ser aplicada para algas de morfologia semelhante à de $P$. capillacea.

\section{Bibliografia}

BLINKS, L. R. 1955. Photosynthesis and productivity of littoral marine algae. J. mar. Res., 14(4):363-373.

DOTY, M. S. 1967. Improvement and application of benthic algal isotope productivity measuring methods. Hawaii Bot. Sci., 3:28-42.

EMERSON, R. \& GREEN, L. 1934. Manometric measuring of photosynthesis in the marine alga Gigartina. J. gen. Physiol., 17:817-843.

GAARDER, T. \& GRAN, H. H. 1927. Investigation of the production of plankton in the Oslo Fjord. Rapp. P.-v Réun. Cons . perm. int. Explor. Mer, 42:1-48.

GOLDMAN, C. R. 1961. The measurement of primary productivity and limiting factors in freshwater with $\mathrm{C}^{14}$. In: Doty, M. S., ed. - Proc. Conf. Primary Productivity Measurement, Marine and Freshwater. Honolulu, Univ. Hawaii, p. 103-113.

GR $\phi$ NTVED, J. 1958. Underwater macrovegetation in shallow coastal waters. J. Cons. perm. int. Explor. Mer, 24(1):142 .

HARVEY, H. W. 1955. The chemistry and fertility of the sea waters. Cambridge, Cambridge University Press, 217p.

JOLY, A. B. 1965. Flora marinha do 1itoral norte do Estado de São Paulo e regiões circunvizinhas. Bolm. Fac. Filos. Ciênc. Letr. Univ. S. Paulo, 294, Bot. 21:1-393.

LEVRING, T. 1947. Submarine daylight and the photosynthesis of marine alge. Göteborgs K. Vetensk.-o. VitterhSamh. Hand1., Ser. B, 5(6): $1-90$. 
MAGLIOCCA, A. 1966. Curso prático de oceanografia: métodos e rotina para determinação de clorinidade, oxìgênio, fosfatos, nitratos e $\mathrm{pH}$ da água do mar. Univ. S. Paulo, Inst. Oceanogräfico e UNESCO, 35p. (mimeografado).

MARTIN, D. F. 1968. Marine chemistry: analytical methods. New York, Marcel Dekker Inc., v.1.

MONTGOMERY, H. A. C.; THOM, N. S. \& COCKBURN, A. 1964. Determination of dissolved oxygen by the Winkler method and the solubility of oxygen in pure water and sea water. J. appl. Chem., $14: 280-296$.

ODUM, E. P.; KUENZLER, E. J. \& BLUNT, M. X . 1958. Uptake of $\mathrm{P}^{32}$ and primary productivity in marine benthic algae. Limno1. Oceanogr., 3(3):340-345.

OLIVEIRA FILHO, E. C. de \& SAZIMA, I. P. 1973. Estudos sobre abiologia de algas agarófitas. I - Recolonização, brotamento e fenologia em populações naturais de Pterocladia capillacea (Rhodophyta - Gelidiaceae). Bolm Zool. Biol mar., n. s., 30:677-690.

POMEROY, L. R. 1959. Algal productivity in Georgia salt marshes. Limnol. Oceanogr., $4: 386-398$.

1961. Isotopic and other techniques of measuring benthic primary production. In: Doty, M. S., ed. - Proc. Conf. Primary Productivity Measurement, Marine and Freshwater. Honolulu, Univ. Hawaii, p.97-102.

PRATT, D. M. \& BERKSON, H. 1959. Two sources of error in the oxygen light and dark bottle method. Limnol. Oceanogr., $4: 328-334$.

QASIN, S. Z. \& BHATTATHIRI, P.M.A. 1971. Primary production of a seagrass bed on Kavaratti Atoll (Laccadives). Hydrobiologia, 38(1):29-38.

RYTHER, J. H. 1954. The ratio of photosynthesis to respiration in marine plankton algae and its effect upon the measurement of productivity. Deep Sea Res., 2(2):134-139.

1956. Photosynthesis in the ocean as a function of light intensity. Limno1. Oceanogr., 1(1):61-70.
STEELE, J. H. 1956. Plant production on the Flafen Ground. J. mar. biol. Ass . U. K., 35:1-33.

STEEMAN-NIELSEN, E. 1952 The use of radio-active carbon $\left(\mathrm{C}^{14}\right)$ for measuring organic production in the sea. $\mathrm{J}$. Cons. perm. int. Explor. Mer, 18:117140 .

STRICKLAND, J. D. H. 1958. Solar radiation penetrating the ocean. A review of requeriments, data and methods of measurements, with particular reference to photosynthetic productivity. J. Fish. Res. Bd Can., 15(3):453-493.

1968. A pratical handbook of sea water analysis. Bul. Fish. Res. Bd Can., (167): 1-311.

TALLING, J. F. 1965. Comparative problems of phytoplankton production and photosynthetic productivity in a tropical and a temperate lake. Memorie Ist. ital. Idrobio1., 18(Sup1.):399-424,

TEIXEIRA, C. 1969. Estudo sobre algumas características do fitoplâncton da região de Cananéia e o seu potencial fotossintético. Tese de doutoramento. Univ. S. Paulo, Fac. Fil. Ciênc. Letr., 82p. (mimeografado).

$$
\text { \& KUTNER, M. B. } 1963 .
$$

$\mathrm{Plankton}$ studies in a mangrove environment. I. First assessment of standingstock and principal ecological factors. Bolm Inst. oceanogr., S Paulo, 12(3): 101-124.

$$
\text { \& TUNDISI, J. G. } 1967 .
$$

Primary production and phytoplankton in equatorial waters. Bul1. mar. Sci., $17(4): 884-891$.

YCAZA, J. 1969. Plankton studies in a mangrove environment. VI. Primary production, zooplankton, standing-stock and some environmental factors. Inst. Revue ges. Hydrobiol. Hydrogr., 54(2): 289-301.

TSENG, C. K. \& SWEENEY, B. M. 1946. Physiological studies of Gelidium cartilagineum. I. Photosynthesis, with special reference to the carbon dioxide factor. Am. J. Bot., 33:706-715.

TUNDISI, J. G. 1969. Produção primäria, "standing-stock" e fracionamento do fi- 
toplâncton na região lagunar de Cananéia. Tese de doutoramento. Univ. S. Paulo, Fac. Fil. Ciênc. Letr., 130p. (mimeografado).

VACCARO, R. F. \& RYTHER, J. H. 1954. The bactericidal effects of sunlight in relation to light and dark bottle photosynthesis experiments. J. Cons. perm. int. Explor. Mer, 20:18-24.

VERDUIN, J. 1956. Primary production in

1akes. Limno1. Oceanogr., 1:85-91.

1960. Phytoplankton communities of western Lake Erie and the $\mathrm{CO}_{2}$ and the $\mathrm{O}_{2}$ changes associated with them. Limnol. Oceanogr., 5:372-380.

VOLLENWEIDER, R. A., ed. 1969. A manual on methods for measuring primary production in aquatic environments. London, International Biological Programme, 213p. (I. B. P. Handbook, n? 12).

WESTLAKE, D. F. 1965. Some basic data for investigations of the productivity of aquatic macrophytes. Memorie Ist. ital. Idrobiol., 18(Sup1.):229-248.

(Recebido em 20/janeiro/1978) 